\title{
In memoriam Doc. RNDr. Václav Ducháč, Ph.D, 1952-2004
}

Es fällt schwer zu glauben, dass bereits beinahe zwei Jahre vergangen sind seit dem vorzeitigen Tod unseres Kollegen Václav Ducháč. Geboren am 9. November 1952 in Náchod, begeisterte er sich schon früh für die Zoologie. Später konzentrierte er sich auf die Pseudoskorpione, und dank seiner unermüdlichen Arbeit wissen wir heute in der Tschechischen Republik unvergleichbar mehr über diese Gruppe als noch vor zwanzig Jahren.

Václav Ducháč absolvierte sein Biologiestudium an der Naturwissenschaftlichen Fakultät der Karls-Universität in Prag mit der Diplomarbeit

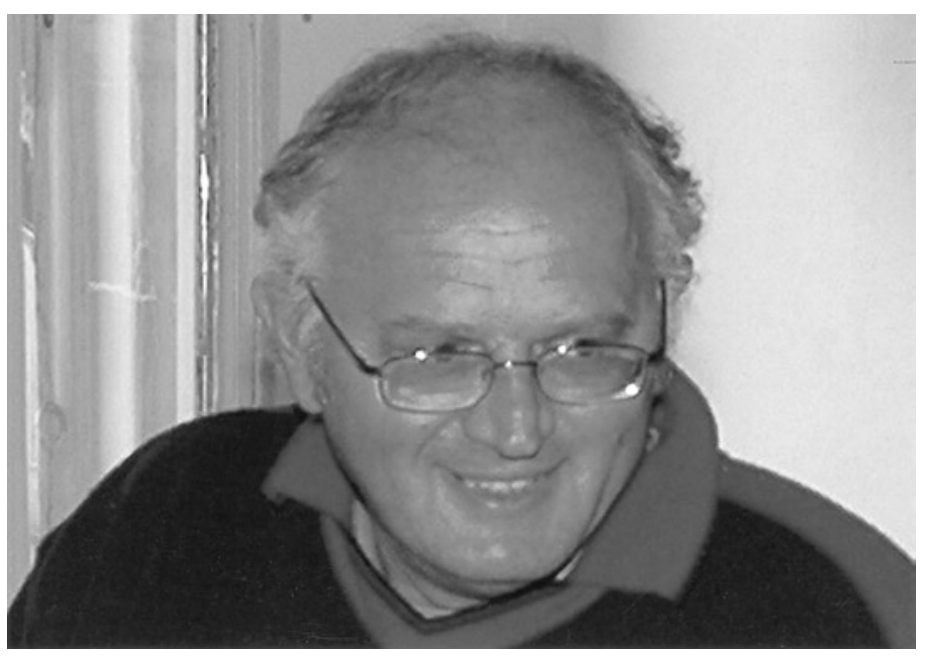
"Larven der tschechoslowakischen Untergattungen Bradytus, Pseudosbradytus und Curtonotus (Amara, Carabidae)". Nach weiterem Studium verteidigte er im Jahre 2002 seine Dissertationsarbeit "Eutroglobionte Pseudoskorpione der Untergattung Blothrus der Westkarpaten" und im Jahre 2003 seine Habilitationsarbeit "Geschichte und gegenwärtiger Kenntnisstand der Pseudoskorpionfauna (Arachnida: Pseudoscorpiones) der Tschechischen Republik" an der Naturwissenschaftlichen Fakultät der Palacky Universität in Olomouc.

Sein breitgefächertes Naturwissen konnte er während seiner reichen pädagogischen Praxis verwerten. Er unterrichtete zwanzig Jahren lang an Gymnasien in seiner ostböhmischen Heimat, vier Jahre in Jilemnice gefolgt von sechzehn Jahren in Náchod. Seine professionelle Laufbahn fand danach ihren Höhepunkt mit der Anstellung an der pädagogischen Fakultät der ostböhmischen Universität in Hradec Králové.

Václav war begeisterter Zoologe und interessierte sich für eine Vielzahl von Wirbellosengruppen (unter anderem für Pseudoscorpiones, Diptera, Coleoptera, Isopoda und Mollusca). In der Arachnologie widmete er seine Aufmerksamkeit den Pseudoskorpionen. Er knüpfte zwar unmittelbar an die Arbeit und das Material P. H. Verners an, war dennoch im Grunde nach A. Stecker (der am Ende des detailliert und langfristig dieser wenig erforschten Gruppe widmete. Václav beschäftigte sich anfangs vorwiegend mit die Faunistik der Pseudoskorpione in der Tschechischen Republik. Im Vergleich mit den Nachbarstaaten war nämlich in Tschechien nur sehr wenig über das Vorkommen und die Verbreitung der Vertreter dieser Gruppe bekannt. In kurzer Zeit gelang es Václav, diesen Mangel zu beheben und für Tschechien eine Vielzahl an Arten zu dokumentieren, die bereits aus den Nachbarstaaten bekannt waren. Bald erweiterte sich sein Interesse über die Faunistik hinaus, und er begann sich der Variabilität in der Außenmorphologie ausgesuchter Arten zu widmen, von der er zum Studium der Genitalien der Gattung Neobisium überging. In letzter Zeit konzentrierte er sich in Zusammenarbeit mit R. Mlejnek auf die Höhlenfauna.

In den 17 Jahren, in den er sich den Pseudoskorpionen widmete, publizierte er mehr als 30 wissenschaftliche Artikel und andere Beiträge. Er starb völlig unerwartet am 19.11.2004 und seine Arbeit, insbesondere seine Forschung an der Höhlenfauna, blieb leider unbeendet. Derzeit ist seine unfangreiche Sammlung der Pseudoskorpione an der Abteilung für Zoologie der Naturwissenschaftlichen Fakultät der Prager Karls-Universität deponiert.

František Štáhlavský dem Gebiet der Tschechischen Republik, die sich 


\section{Artikel über Pseudoskorpione}

DUCHÁČ V. (1988): Příspěvek k poznání štírků Českého středohoří. - Fauna Bohemiae Septentrionalis 13: 103-108

DUCHÁČ V. (1989): Einige Funde von Afterskorpione aus der Umgebung der Universität in Debrecen (Pseudoscorpionidea). - Acta Biol. Debrecina 21: 117-120

-- (1989): Př́ispěvek k faunistice štírků Československa (Pseudoscorpionidea). - Zbor. Slov. nár. Múz., Prír. Vedy, Bratislava. 35: 179-182

DuCHÁČ V. (1993): Štírci (Pseudoscorpionidae) ze stromových dutin na Třeboňsku.- Sbor.Jihočes. Muz. v Čes. Budějovicích, Přír. Vědy 33: 65-69

-- (1993): Zwei neue Afterskorpion-Arten aus der Tschechischen Republik. - Arachnol. Mitt. 5: 36-38

DUCHÁČ V. (1994): Faunistiko-bionomické poznámky k některým druhům štírků České a Slovenské republiky. - Fauna Bohemiae Septentrionalis 19: 139-153

DuCHÁČ V. (1995): Beitrag zur Kenntnis der Morphologie des Pseudoskorpions Neobisium polonicum (Pseudoscorpionidea: Neobisiidae) und seiner Verbreitung in der Slowakei. - Klapalekiana 31: 11-17

-- (1995): Pseudoscorpionida. In: ROZKOŠNÝ R. \& J. VAŇHARA (Hrsg.): Terrestrial invertebrates of the Pálava Biosphere Reserve of UNESCO. - Folia Fac. Sci. Nat. Univ. Masarykianae Brunensis, Biologia 92: 51-53

-- (1995): Variabilita určovacích znaků Neobisium fuscimanum (Pseudoscorpionidea). - Fauna Bohemiae Septentrionalis 20: 145-151

DUCHÁČ V. (1996): Über Neobisium (Blothrus) slovacum (Pseudoscorpiones: Neobisiidae) aus der BrzotínHöhle in der Slowakischen Republik. - Klapalekiana 32: 153-157

-- (1996): Nález Chthonius cf. kewi (Pseudoscorpiones) v České republice. - Východočeský sborník př́rodovědný-Práce a studie 4: 81-84

DuCHÁČ V. (1997): Dosavadní nálezy štírků (Pseudoscorpiones) v Adršpašsko - Teplických skalách. - Vč. Sb. Př́r.-Práce a studie 5: 117-119

DUCHÁČ V. (1998): Erstnachweis von Syarinus strandi in der Tschechischen Republik (Arachnida: Pseudoscorpiones). -Entomol. Z. 108: 506-508

-- (1998): Nachweis der Art Neobisium simile (Arachnida, Pseudoscorpiones) im Vorgebirge des Teutoburger Waldes. - Arachnol.e Mitt. 15: 84-86

DuCHÁČ V. (1999): Merkmale zur Bestimmung der Art Neobisium (Blothrus) slovacum (Arachnida: Pseudoscorpiones). - Entomol. Z. 109: 175-180
-- (1999): Fund der Art Withius hispanus (L. Koch 1873) in Südbulgarien (Pseudscorpiones, Withiidae). - Entomol. Z. 109: 496-498

-- (1999): Morfologie pedipalpů Neobisium carcinoides (Pseudoscorpiones: Neobisiidae) z České republiky. - Vč. Sb. Př́r.-Práce a studie 7: 105-113

-- (1999): The contemporary research of the pseudoscorpion fauna in the Czech Republic. - American Arachnology 59: 14

-- (1999): Rozšiŕřenie štúrika Neobisium polonicum (Neobisiidae) v Slovenskej republike. - Natura Carpatica 40: 207-210

DUCHÁČ V. (2000): Historie výzkumu karpatských eutroglobiontních štírku podrodu Blothrus (Neobisium: Neobisiidae: Pseudoscorpiones). In: Mock A., L. KovÁČ \& M. FuLín (eds): Fauna jaskýň - Cave fauna. Východoslovenské múzeum, Košice, pp. 7-13

-- \&R.MLeJNEK (2000): Records of the Pseudoscorpion Neobisium (Blothrus) slovacum (Neobisiidae) in caves and chasms of the Slovak Karst. In: MocK A., L. KOVÁČ \&M. FULíN (eds): Fauna jaskýň - Cave fauna. Východoslovenské múzeum, Košice, pp. 15-20

-- \& R. MlejneK (2000): Neobisium slovacum - nejsevernejší eutroglobiontní štírek Evropy. - Speleofórum 19: 48-49

DUCHÁČ V. (2001): Zoogeography of European cavedwelling pseudoscorpion fauna of the Neobisium-complex. - American Arachnology 63: 8-9

ŠŤÁHLAVSKÝ F. \& DUCHÁČ V. (2001): Neue und wenig bekannte Afterskorpion-Arten aus der Tschechischen Republik. - Arachnol. Mitt. 21: 46-49

DUCHÁČ V. (2002): An anomaly of chaetotaxy of pedipalpal chela in Neobisium carcinoides (Arachnida: Pseudoscorpiones). - Arachnol. Mitt. 23: 58-59

-- \& R. MLEjNEK (2002): K nejsevernějšímu výskytu jeskynního štírka v Evropě. - Živa 50/3: 125

DUCHÁČ V. (2003): Die männlichen Genitalstrukturen der Neobisium-Arten der Tschechischen Republic (Pseudoscorpiones: Arachnida). - Entomol. Z. 113: 2-6

Blick T., C. Muster \& V. DuchÁČ (2004): Checkliste der Pseudoskorpione Mitteleuropas. Checklist of the pseudoscorpions of Central Europe. (Arachnida: Pseudoscorpiones). Version 1. Oktober 2004. - Internet: http://www.AraGes.de/checklist.html\#2004_ Pseudoscorpiones

DUCHÁČ V. (2004): Male genitalia of eutroglobiotic pseudoscorpions Neobisium slovacum, Neobisium lerutbi, and Neobisium aueri (Pseudoscorpiones: $\mathrm{Ne}-$ obisiidae). - Mitt. Internat. Entomol. Ver. 29: 51-57 -- (2004): Male genitalia of Protoneobisium biocovense 
(Pseudoscorpiones: Neobisiidae). - Biologia, Bratisl. 59: 289-291

-- (2004): Einige Funde von Afterscorpionen (Pseudoscorpiones) auf Helgoland. - Arachnol. Mitt. 27/28: 74-77

-- \& R. MLejneK (2004): Der Fund der Art Neobisium svetovidi (Pseudoscorpiones: Neobisiidae) in der Schlucht Veliko Grotlo. - Mitt. Internat. Entomol. Ver. 29: 93-100

ŠTÁHLAVSKÝ F. \& V. DUCHÁČ (in press): Pseudoscorpiones (štírci). In: FARKAČ J., D. KRÁL \& M.- ŠKORPÍK (eds): Červený seznam ohrožených druhů České republiky. Bezobratlí. [Red list of threated species in the Czech Republic. Invertebrates]. AOPK CR, SOP ČR, Praha.

\section{Abstracts über Pseudoskorpione}

DUCHÁČ V. (1994): Stav a zaměření výzkumu fauny štírků České republiky. In: Zoologické dny Brno 1994. Abstrakta referátů z Konference 3. a 4. listopadu 1994.
DUCHÁČ V. (1995): Novější poznatky o fauně štírkủ (Pseudoscorpionidea) České republiky.In: Zoologické dny Brno 1995. Abstrakta referátů z Konference 9. a 10. listopadu 1995. Česká zoologická společnost, Brno,

DuCHÁČ V. (1997): Eutroglobiontní štírci podrodu Blothrus (Neobisium, Pseudoscorpiones) Slovenského krasu. Sbor. Abstr. 9. sjezdu čs. Zoologů, České Budějovice.

DUCHÁČ V. (1998): Dosavadní nálezy štírků (Pseudoscorpiones) ve Sloveských jeskyních. Zborník referátov z mezinárodnej vedeckej konferencie. Biologické dni Nitra 2.-4.9.1998, 112-113

-- (1998): Červený seznam ohrožených štírků Německa a fauna štírkủ České republiky. In: Zoologické dny Brno 1998. Abstrakta referátů z Konference 5. a 6. listopadu 1998. Česká zoologická společnost, Brno, unpaginated

Ducháč V. \& R. MLejneK (2003): Nové lokality štírků rodu Neobisium na území bývalé Jugoslávie. In: Zoologické dny Brno 2003. Abstrakta referátů z Konference 13. a 14. února 2003. Česká zoologická společnost, Brno, 28-29 